\title{
LANCE: Laccase-nanoparticle conjugates for the elimination of micropollutants (endocrine disrupting chemicals) from wastewater in bioreactors
}

\author{
Philippe F. X. Corvini · Patrick Shahgaldian
}

Published online: 18 November 2009

(C) Springer Science+Business Media B.V. 2009

\begin{abstract}
Elimination of recalcitrant chemicals during wastewater treatment is a difficult problem for both developing and industrialized countries. The biological elimination of very persistent xenobiotics such as endocrine disrupting chemicals from municipal and industrial sewage treatment plants is an ambitious challenge as existing physico-chemical methods, such as advanced oxidation processes, are energy-intensive and consume high amounts of chemicals. Through the entry into force of strict legislative measures, such as the Water Framework Directives (EU WFD in Directive 2000/60/EC of the European Parliament and of the Council establishing a framework for the Community action in the field of water policy, 2000) and REACH (REACH EU in European Community Regulation on chemicals and their safe use (EC 1907/2006), 2007), the market for wastewater treatment is exploding. For instance the European market potential for the membrane bioreactor technology is estimated to $57 \mathrm{M} €$ per year.
\end{abstract}

P. F. X. Corvini ( $\square)$

Institute for Ecopreneurship, School of Life Sciences,

University of Applied Sciences Northwestern

Switzerland, Gründenstrasse 40, 4132 Muttenz,

Switzerland

e-mail: philippe.corvini@ fhnw.ch

P. Shahgaldian

Institute for Chemistry and Bioanalytics, School of Life

Sciences, University of Applied Sciences Northwestern

Switzerland, Gründenstrasse 40, 4132 Muttenz,

Switzerland
Based on recent progresses in nanotechnology, new developments in catalysis and environmental applications can be foreseen for the near future. Indeed, because of high surface area-to-volume ratio in nanosystems, heterogeneous enzymatic or catalytic reactions can be greatly enhanced. In the LANCE project a nanoparticle (NP)-based technology is under development. Cheap and resistant oxidative enzymes, i.e. laccases are immobilized onto the surface of the particles in order to produce systems possessing a broad substrate spectrum for the degradation of cocktails of recalcitrant pollutants. One of the objectives is to produce NPs that are compatible with wastewater treatment and can be synthesised in a cost-effective and large-scale fashion, e.g. silicabased NPs using flame spray pyrolysis and emulsionbased techniques. The modified particles are applied in bioreactors where they are retained, i.e. membrane bioreactors or perfusion basket reactors to eliminate pollutants from the wastewater. Such reactors allow multi-cycle use of the NPs coated with active enzymes and thus contribute to decrease the treatment costs. The two-year activities of the LANCE project encompass the synthesis of various NP systems, the immobilization of selected low cost industrial laccases on the latter, and the technical and scientific proof of the "depollution" concept.

Keywords Nanoparticles · Laccase · Enzyme immobilization - Endocrine disrupters · Fixed-bed $\cdot$ Membrane bioreactor 


\section{Introduction}

Pharmaceuticals and other hormonally active chemicals are often detected in wastewater treatment plant effluents, in surface waters and in groundwater (Cirja et al. 2008). Wastewater treatment plants (WWTP) have been evidenced as point sources for release of such substances in the environment, either through discharge of treated effluents or by dispersion of digested sludge on agricultural fields (Halling-Sorensen et al. 1998; Ternes 1998). The main reason for this situation is the insufficient removal of these hardly biodegradable substances by current sewage treatment processes. Adverse effects on ecological systems, e.g. the disturbance of endocrine systems in aquatic organisms, may arise from highly bioactive contaminants (Cirja et al. 2008). Although the severity of such problems remains unclear, caution is required given the large variety of substances in use, e.g. in 2005, 4727 human medicines were registered in Switzerland. ${ }^{1}$ Many substances ingested by humans are transformed in the body (metabolized) and excreted in the urine or faeces (Lienert et al. 2007). The release of organic trace pollutants via WWTP continues to be a challenge for water protection. Micro-pollutants such as pesticides, surfactants, preservatives, solvents, fragrances, flavours and pharmaceuticals as well as endocrine disruptors are thus of concern in the urban water cycle (see e.g. COST action 636 on Xenobiotics in the urban water cycle, http://cost636xenobiotics.er.dtu.dk/).

Besides source control and phasing out of compounds (e.g. as required for priority hazardous pollutants under the water framework directive, WFD), the upgrade of WWTP seems to be an option. Several advanced technologies for the elimination of micro-pollutants in the wastewater treatment systems are under development, i.e. oxidation, filtration, adsorption, biodegradation etc. (Corvini et al. 2006; Esplugas et al. 2007; Klavarioti et al. 2009).

Such technologies must fulfil, amongst others, criteria such as the easy and space saving integration in existing municipal and industrial WWTP, cost effectiveness, the absence of environmental sideeffects and low energy consumption. Novel wastewater treatment technologies for the elimination of

\footnotetext{
${ }^{1}$ http://www.novaquatis.eawag.ch/arbeitspakete/nova5/index _EN
}

micro-pollutants are especially challenging. The techniques should be generally applicable to a wide range of micro-pollutants possessing diverse physicochemical properties. Relative to the trace amounts of pollutants to be removed, the costs of the technologies, because of the needs for chemicals and energy, are in general very high and/or need important investments.

\section{Background}

Laccases are metal-containing enzymes capable of oxidizing numerous phenolic substrates by one electron abstraction. Laccases have been reported to be efficient biocatalysts for the degradation of several micro-pollutants including Endocrine Disrupting Chemicals (EDC) such as bisphenol A, estradiol, ethinylestradiol, triclosan, nonylphenol, etc. (Cabana et al. 2007a); polycyclic musk fragrances such as galaxolide and tonalide (Martin et al. 2007), persistent organic pollutants such as polychlorinated biphenyls, polycyclic aromatic hydrocarbons, and dyes (Haglund et al. 2002). Nonetheless, the application of enzymes in continuous systems such as WWTP remains a challenge since the biocatalysts are easily washed out under the hydraulic retention time conditions that are usually applied $(<10 \mathrm{~h})$. Recent efforts have been focused on the immobilization/encapsulation of biocatalysts in order to tackle this major limitation and to facilitate their possible reuse (Stanescu et al. 2009). Among the different approaches tested, Cabana et al. (2007b) have developed cross-linked enzyme aggregates (CLEAs) from laccases of the white rot fungal strain Coriolopsis polyzona to degrade EDC. The same authors demonstrated that laccase immobilized on celite (Cabana et al. 2009a) or CLEA of laccase (Cabana et al. 2009b) possess the ability to efficiently degrade nonylphenol, bisphenol A and triclosan in a packed bed reactor and in a perfusion basket reactor, respectively. Although laccases are capable of oxidizing numerous phenolic substrates, the use of this enzyme for remediation applications is rather limited to its soluble form. Based on the development of novel nano-materials, emerging perspectives for new supports for enzyme immobilization are becoming a reality. For instance, it has been demonstrated that laccase immobilized on hexagonal mesoporous silica (SBA-15) nanoparticles (NP) was more stable 
against $\mathrm{pH}$ and temperature changes $\mathrm{Hu}$ et al. (2007), (2009).

\section{Objectives and concept of the LANCE project}

The concept of the LANCE project is the application of laccase immobilized onto nano-materials for the treatment of effluents contaminated by xenobiotics in adapted bioreactors retaining the NPs (Fig. 1).

The immobilization of the biocatalysts onto a solid support can reduce the enzyme loss, limit the denaturation problems, and facilitate their possible reuse. Silicon dioxide offers a high versatility (particle size, surface area, porosity, surface chemistry, ease of synthesis, and scalability) and represents the support of choice for the enzymatic immobilisation. Furthermore, silica materials are considered neutral and nontoxic and occur in natural environments. Different synthesis routes of nano-particulate materials exist or are under development. They comprise micro- and mini-emulsion-based techniques, monophasic synthesis according to the method of Stoeber et al. (1968) and flame spray pyrolysis (FSP). The immobilization technique is based on the covalent attachment of oxidative enzymes on these nanoparticles. Laccase is the biocatalyst of choice as it is a robust and versatile oxidative enzyme, which can be used in a wide range of biotechnological and environmental applications such as the synthesis of new dyes and the treatment of contaminated effluents. Furthermore, this enzyme does not require the addition of cofactors or substrates beside oxygen. With the emergence of membrane, cascade fixed bed (Fig. 2), and perfused basket reactors (Cabana et al. 2009b), new perspectives are opened concerning the use of NP for the treatment of wastewater. Due to physical separation (retention) steps, such reactors enable the retention of any form of fine suspended solids and are thus suited for the recycling of the functionalized nano-particulate materials. In the case of the cascade fixed-bed reactors functionalized nanoparticles are applied in the last chamber of the system before the filtration step (Fig. 2). At this stage of the process, the organic load remaining in wastewater is rather low and the growth of microorganisms strongly limited. This presents the advantage of controlling the biofouling of the enzyme coated nano-material. Furthermore, the use of composite materials as immobilization support, e.g. silica scaffold containing nano-particles of silver, may help preventing biofilm formation through the release of silver cations.

The originality of this project relies on two major innovations:

1. The type of nano-materials on which laccase is immobilized (to produce novel enzymatic active nano-materials)
a. Composite silica NP synthesized by FSP
b. Silica NP synthesized by micro- and mini- emulsion and monophasic syntheses

2. The application of enzyme active nano-materials to two novel reactors

a. Combination of the cascade fixed-bed reactor with membrane technology
b. Perfused basket bioreactor with membrane technology

Fig. 1 Concept of the LANCE project

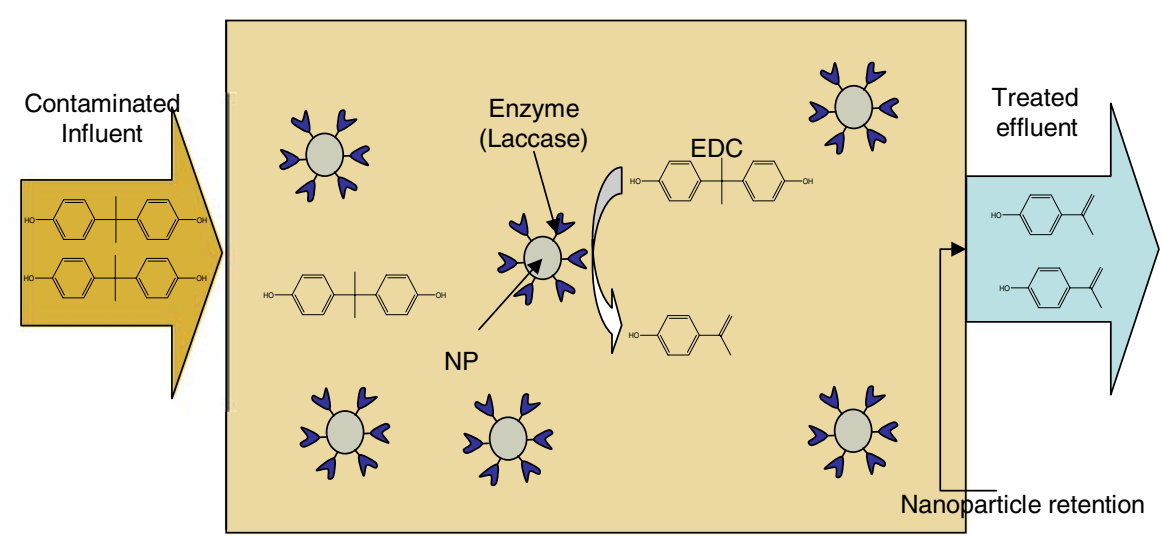




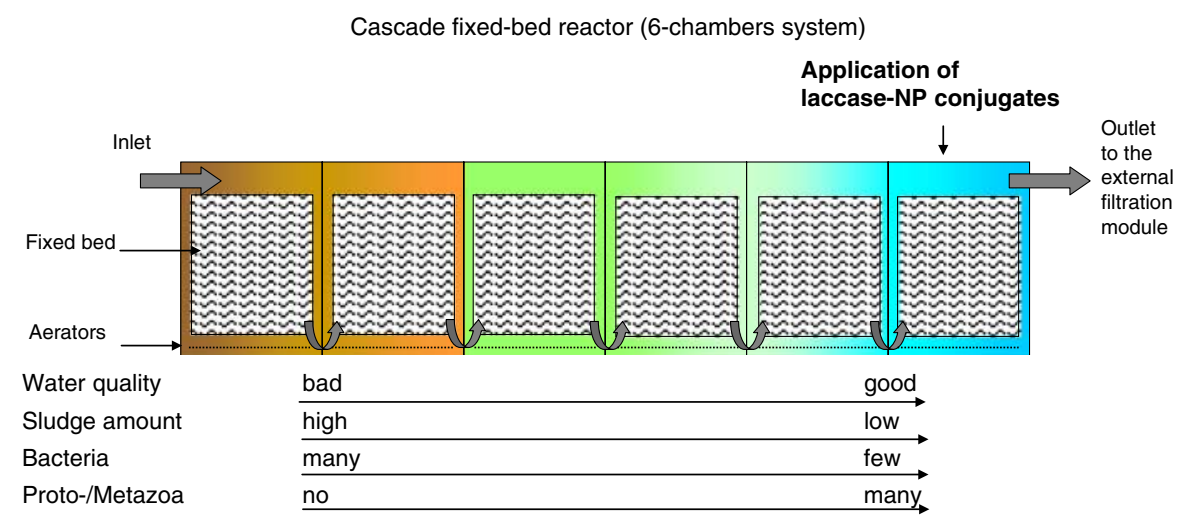

Fig. 2 Cascade fixed-bed reactor used for wastewater treatment and the application of the modified nanoparticles. The sewage water is treated in six successive chambers, each containing a fixed-bed made of polyethylene, which serves as immobilization material for microorganisms. As the wastewater passes successively from one chamber to the next one, the

Furthermore, the activities of the project are accompanied by ecotoxicological assessments of possible risks related to the production of degradation intermediates and accidental release of nanomaterials. In the perspective of developing a sort of green water quality increases (e.g. decrease in the chemical oxygen demand content) and the amount of produced biomass (sludge) simultaneously decreases. The laccase-nanoparticle conjugates are added at an advanced stage of the treatment (i.e. 6th chamber) before the effluent and added conjugates are treated by means of a ultrafiltration step

labelled technology a panel of general ecotoxicity and specific tests are used.

The advances of the LANCE project are monitored with respect to five milestones:

Table 1 Partners in the LANCE project

\begin{tabular}{|c|c|}
\hline Partner & Expertise \\
\hline $\begin{array}{l}\text { University of Applied Sciences of Northwestern Switzerland, } \\
\text { School of Life Sciences, Institute for Ecopreneurship and } \\
\text { Institute for Chemistry and Bioanalytics, Switzerland }\end{array}$ & $\begin{array}{l}\text { Coordination, synthesis of nanoparticles, enzymology and protein } \\
\text { chemistry, wastewater treatment, (radio)analytics, } \\
\text { ecotoxicology }\end{array}$ \\
\hline University of Basel, Switzerland & $\begin{array}{l}\text { Chemical synthesis and nanoparticle characterisation and } \\
\text { functionalization }\end{array}$ \\
\hline HeiQ Materials, Switzerland & $\begin{array}{l}\text { Production of nanomaterials, flame spray pyrolysis, silver doped } \\
\text { silica nanomaterials }\end{array}$ \\
\hline Aquaren $^{\mathrm{a}}$, Switzerland & $\begin{array}{l}\text { Construction of wastewater treatment plants and plants for } \\
\text { environmental technology applications }\end{array}$ \\
\hline MMS, Switzerland & $\begin{array}{l}\text { Application of membrane processes to wastewater treatment, } \\
\text { scale-up of membrane processes, membrane system design, } \\
\text { engineering and construction }\end{array}$ \\
\hline Amt für industrielle Betriebe, Switzerland & Operation of wastewater treatment plants \\
\hline Balewa, Switzerland & $\begin{array}{l}\text { Environmental biotechnology, process technology and } \\
\text { application }\end{array}$ \\
\hline Wetlands incubator SPRL, Belgium & $\begin{array}{l}\text { Biotechnology, laccase production, equipments for environmental } \\
\text { applications }\end{array}$ \\
\hline Université Catholique de Louvain-GEBI, Belgium & $\begin{array}{l}\text { Covalently linked enzyme aggregates, environmental } \\
\text { biotechnology }\end{array}$ \\
\hline SINTEF, Norway & $\begin{array}{l}\text { Nano-particle syntheses, emulsion-based techniques, enzyme } \\
\text { immobilisation, scale-up }\end{array}$ \\
\hline
\end{tabular}

a Aquaren benefits from the support of the Swiss Federal Office of the Environment 
- Production of gram and kilogram quantities of highly functional materials - and development of an optimized immobilisation procedure

- Establishment of the procedure necessary to evaluate the yields of enzyme immobilisation and the efficiency of wastewater treatment

- Scale up of the functional nanoparticles to multi $\mathrm{kg}$ scale

- Proof of the concept at lab-scale

- Proof of the concept at semi-pilot scale on-site at a WWTP.

\section{The LANCE consortium}

LANCE is a project, which has been initiated in the frame of the ERA-Net Materials "MATERA" call for proposals (EU FP6). MATERA is a cooperation platform, which aims at supporting national and regional science and technology authorities to effectively diffuse and transfer knowledge and skills obtained from research academia for utilisation in business and industrial enterprises. The LANCE partners entered into contracts with their national institutions, i.e. Swiss Commission for Technology and Innovation (Switzerland), Research Council of Norway (Norway), and the Walloon Region (Belgium). The 24-month project started in September 2009 and includes ten partners from academia, industry and local institutions of three countries (Table 1).

Acknowledgments The partners of the project LANCE acknowledge the Swiss Commission for Technology and Innovation, the Swiss Federal Office of the Environment, the Research Council of Norway, and the Walloon Region for their financial support. The authors thank S. Agathos, C. Junghanns, F. Linners, R. Schmidt, and P. Stenstad for critical reading of the manuscript.

\section{References}

Cabana H, Jones JP, Agathos SN (2007a) Elimination of endocrine disrupting chemicals using white rot fungi and their lignin modifying enzymes: a review. Eng Life Sci 7:429-456

Cabana H, Jones JP, Agathos SN (2007b) Preparation and characterization of cross-linked laccase aggregates and their application to the elimination of endocrine disrupting chemicals. J Biotechnol 132:23-31

Cabana H, Alexandre C, Agathos SN, Jones JP (2009a) Immobilization of laccase from the white rot fungus Coriolopsis polyzona and use of the immobilized biocatalyst for the continuous elimination of endocrine disrupting chemicals. Bioresour Technol 100:3447-3458

Cabana H, Jones JP, Agathos SN (2009b) Utilization of crosslinked laccase aggregates in a perfusion basket reactor for the continuous elimination of endocrine-disrupting chemicals. Biotechnol Bioeng 102:1582-1592

Cirja M, Ivashechkin P, Schäffer A, Corvini PFX (2008) Factors affecting the elimination of organic micropollutants from wastewater in conventional treatment plants (CTP) and membrane bioreactors (MBR). Rev Environ Sci Biotechnol 7:61-78

Corvini PFX, Schäffer A, Schlosser D (2006) Microbial degradation of nonylphenol and other alkylphenols-Our evolving view. Appl Microbiol Biotechnol 72:223-243

Esplugas S, Bila DM, Krause LG, Dezotti M (2007) Ozonation and advanced oxidation technologies to remove endocrine disrupting chemicals (EDCs) and pharmaceuticals and personal care products (PPCPs) in water effluents. J Hazard Mat 149:631-642

EU WFD (2000) Directive 2000/60/EC of the European Parliament and of the Council establishing a framework for the Community action in the field of water policy. Available at: http://ec.europa.eu/environment/water/waterframework/index_en.html

Haglund C, Levín L, Forchiassin F, López M, Viale A (2002) Degradation of environmental pollutants by Trametes trogii. Rev Argent Microbiol 34:157-162

Halling-Sorensen B, Nors Nielsen S, Lanzky PF, Ingerslev F, Holten Lutzhoft HC, Jorgensen SE (1998) Occurrence, fate and effects of pharmaceutical substances in the environment- A review. Chemosphere 36:357-393

Hu X, Zhao X, Hwang HM (2007) Comparative study of immobilized Trametes versicolor laccase on nanoparticles and kaolinite. Chemosphere 66:1618-1626

Hu X, Wang P, Hwang HM (2009) Oxidation of anthracene by immobilized laccase from Trametes versicolor. Bioresour Technol 100:4963-4968

Klavarioti M, Mantzavinos D, Kassinos D (2009) Removal of residual pharmaceuticals from aqueous systems by advanced oxidation processes. Environ Int 35:402-417

Lienert J, Bürki T, Escher BI (2007) Reducing micropollutants with source control: substance flow analysis of 212 pharmaceuticals in faeces and urine. Water Sci Technol 56:87-96

Martin C, Moeder M, Daniel X, Krauss G, Schlosser D (2007) Biotransformation of the polycyclic musks HHCB and AHTN and metabolite formation by fungi occurring in freshwater environments. Environ Sci Technol 41: 5395-5402

REACH EU (2007) European Community Regulation on chemicals and their safe use (EC 1907/2006). Available at: http://ec.europa.eu/environment/chemicals/reach/reach_ intro.htm

Stanescu MD, Fogorasi M, Shaskolskiy BL, Gavrilas S, Lozinsky VI (2009) New potential biocatalysts by laccase immobilization in PVA cryogel type carrier. Appl Biochem Biotechnol. doi: 10.1007/s12010-009-8755-0

Stoeber W, Fink A, Bohn E (1968) Controlled growth of monodisperse silica spheres in the micron size range. J Colloid Interface Sci 26:62-69

Ternes TA (1998) Occurrence of drugs in German sewage treatment plants and rivers. Water Res 32:3245-3260 